\title{
Nachruf Michel Cullin
}

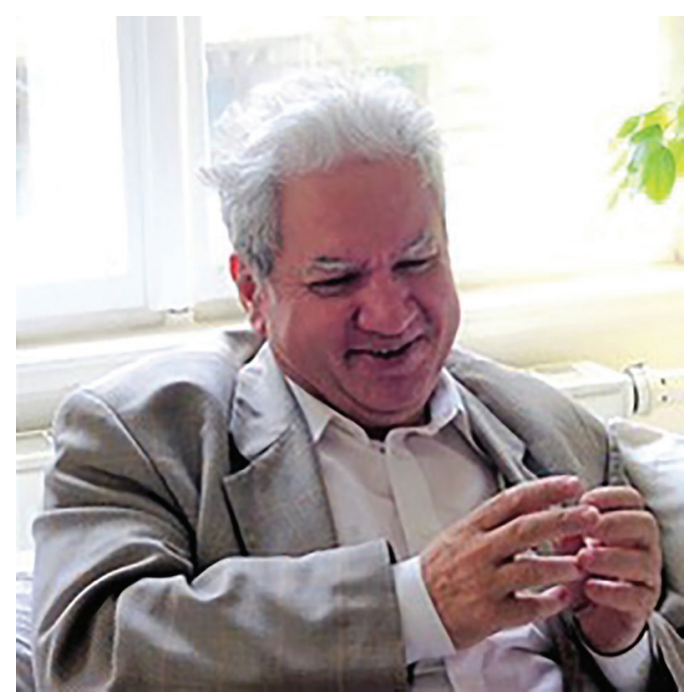

Foto $\odot$ JoDD von Schaffstein

Wir trauern um Michel Cullin, der unmittelbar nach dem Fall der Berliner Mauer als Attaché für die deutsch-französische Hochschulkooperation der Französischen Botschaft in Berlin jenen eine Stimme gab, die in der Zeit des Kalten Krieges aus dem deutsch-französischen Tandem ausgeschlossen waren. Er schuf Räume für Begegnungen zwischen Frankreich und Deutschland, Ost wie West, in denen auf Augenhöhe debattiert und geforscht wurde. In diesem Sinne war er ein engagierter Diplomat und Mittler, der Feindbilder abbauen half und Gestaltungsmöglichkeiten auch für Ostdeutsche in der Frankreichforschung beförderte. Aus diesen Jahren sind andauernde deutsch-französische Kooperationsbeziehungen entstanden. Später wandte er sich im gleichen kooperativen Geist osteuropäischen Ländern, insbesondere dem Kosovo, Belarus und Polen zu. Seine Arbeit im Weimarer Dreieck war ihm eine Herzensangelegenheit. Wir verlieren einen guten Freund.

Dorothee Röseberg, Universitätsprofessorin (i.R.), Martin-Luther-Universität Halle-Wittenberg, Vizepräsidentin der LeibnizSozietät der Wissenschaften zu Berlin

Françoise Bertrand, Professeure agrégée d'allemand, retraitée active, ENSEA Cergy-Pontoise, ADEAF Paris

Prof. Dr. Gilbert Casasus, Université de Fribourg

Dr. Jacqueline Grenz, Leiterin der Sprachkurse am Institut Français Berlin (1991-1995)

Dr. Rainhardt Gutsche, stellv. Direktor des Kulturzentrums der DDR in Paris (1989)

Françoise Knopper, Professeure émérite, Université de Toulouse

Patricia Krauth, Professeure agrégée d'allemand, Université de Strasbourg

Dr. Marie-Therese Mäder, wissenschaftliche Mitarbeiterin, Universität Bremen

Dr. Caroline Moine, maîtresse de conférences en histoire contemporaine, Université Paris-Saclay 
Dr. Stefanie Neubert, Direktorin des Goethe-Instituts Toulouse

JoDD von Schaffstein, Künstler

Arnaud Sète, Sprachattaché der Französischen Botschaft in Berlin (1990-1995) sowie stellv. Büroleiter des DFJW (2000-2005), verantwortlich für den Schüleraustausch 